\title{
Projections of hydrofluorocarbon (HFC) emissions and the resulting global warming based on recent trends in observed abundances and current policies
}

Guus J.M. Velders, John S. Daniel, Stephen A. Montzka, Isaac Vimont, Matthew Rigby, Paul B. Krummel, Jens Muhle, Simon O'Doherty, Ronald G. Prinn, Ray F. Weiss, and Dickon Young

Table S1: Emission factors for calculating the emissions as a fraction of the bank.

\begin{tabular}{lllllll}
\hline Use sector & EU & USA & Japan & $\begin{array}{l}\text { other } \\
\text { OECD }\end{array}$ & Russia & $\begin{array}{l}\text { Developing } \\
\text { countries }\end{array}$ \\
\hline Domestic refrigeration $^{2}$ & 0.025 & 0.025 & 0.025 & 0.025 & 0.025 & 0.025 \\
Commercial refrigeration $^{3}$ & 0.121 & 0.164 & $0.110^{1}$ & 0.117 & 0.084 & 0.110 \\
Transport refrigeration $^{3}$ & 0.126 & 0.202 & 0.122 & 0.172 & 0.115 & 0.159 \\
Industrial refrigeration $^{3}$ & 0.128 & 0.059 & 0.087 & 0.093 & 0.093 & 0.087 \\
Stationary AC $^{3}$ & 0.060 & 0.034 & 0.035 & 0.087 & 0.037 & 0.060 \\
Mobile AC $^{3}$ & 0.101 & 0.127 & 0.049 & 0.133 & 0.116 & 0.113 \\
Foams XPS $^{1}$ & 0.050 & 0.050 & 0.050 & 0.050 & 0.050 & 0.050 \\
Foams PUR $^{1}$ & 0.050 & 0.050 & 0.050 & 0.050 & 0.050 & 0.050 \\
Foams open cell $^{1}$ & 0.670 & 0.670 & 0.670 & 0.670 & 0.670 & 0.670 \\
Aerosols $^{1}$ & 0.670 & 0.670 & 0.670 & 0.670 & 0.670 & 0.670 \\
Fire protection $^{1}$ & 0.030 & 0.030 & 0.030 & 0.030 & 0.030 & 0.030 \\
Solvents $^{1}$ & 0.670 & 0.670 & 0.670 & 0.670 & 0.670 & 0.670 \\
\hline
\end{tabular}

1) Emission factors taken as the average of the developed countries.

2) Same as in (Velders et al., 2015).

3) Derived from the UNFCCC activity data and emissions. 

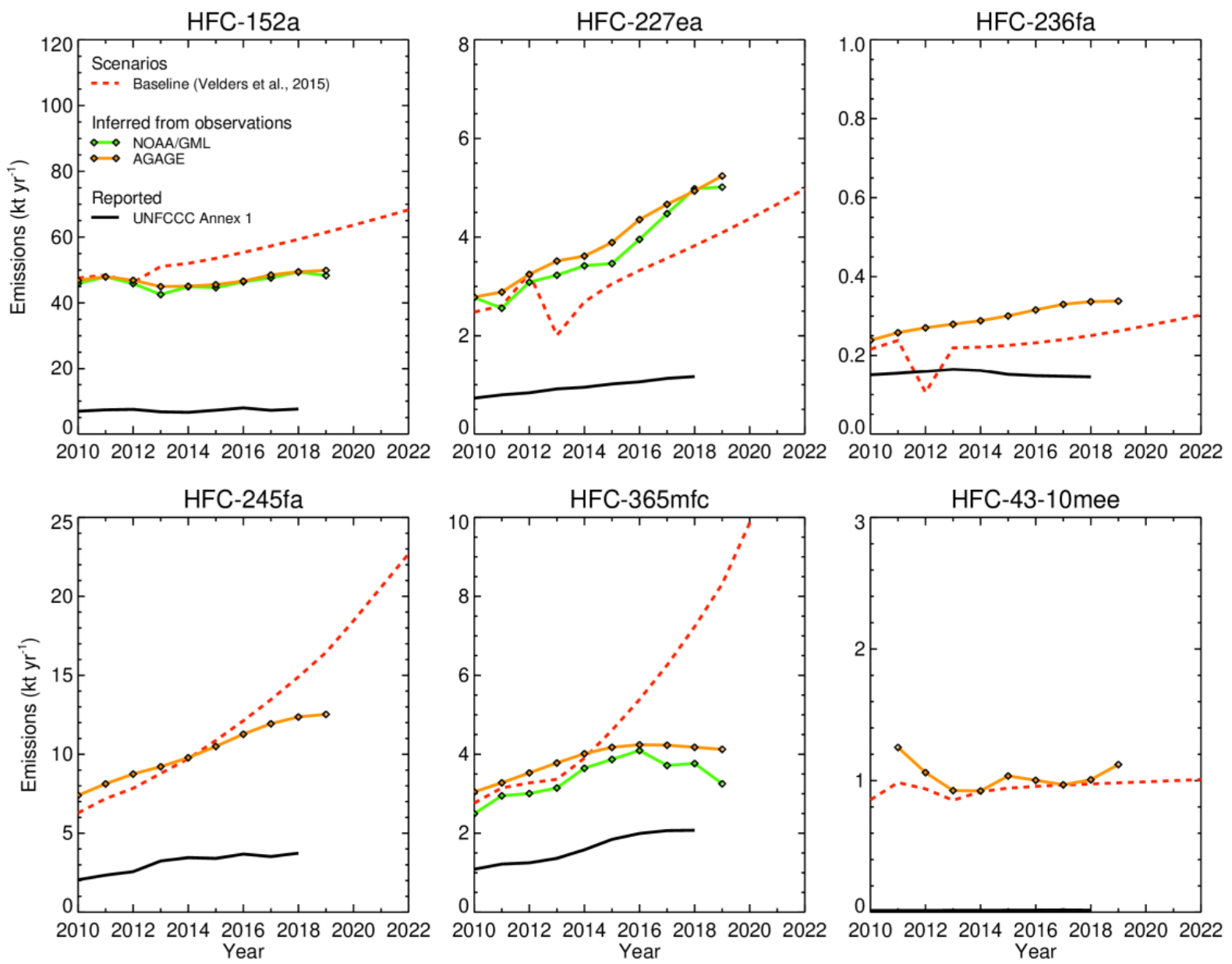

Figure S1: Global total HFC emissions $\left(\mathrm{kt} \mathrm{yr}^{-1}\right)$ from the 2015 baseline compared with emissions inferred from observed mixing ratios from the AGAGE and NOAA/GML networks. Also shown are the emissions reported to the UNFCCC by Annex 1 countries. The scenario emissions were constrained by the emissions inferred from observed mixing ratios up to 2013.
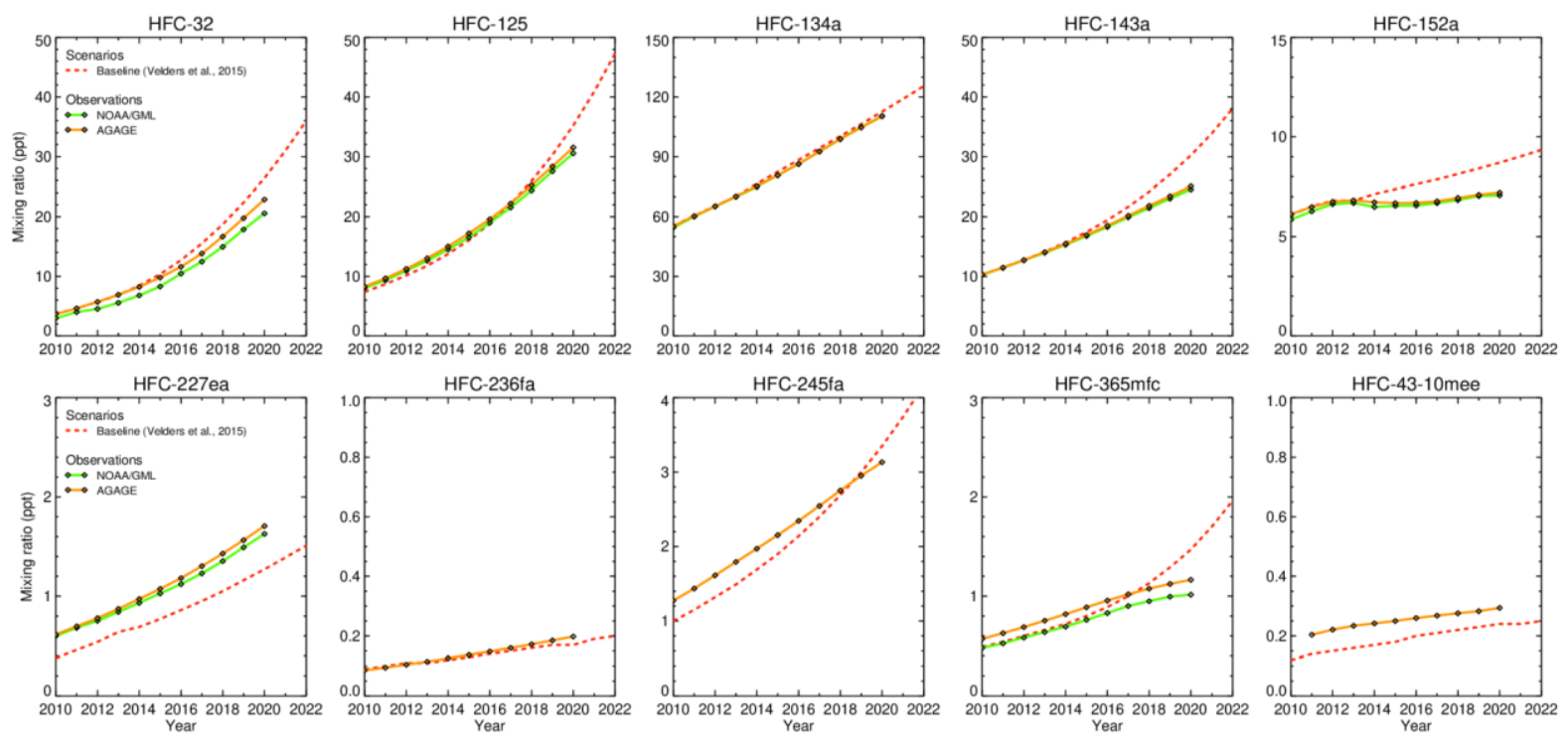

Figure S2: Globally averaged HFC mixing ratios (ppt) from the 2015 baseline scenario compared with observations from the AGAGE and NOAA/GDL networks. The scenarios were constrained to the observed mixing ratios up to 2013. 

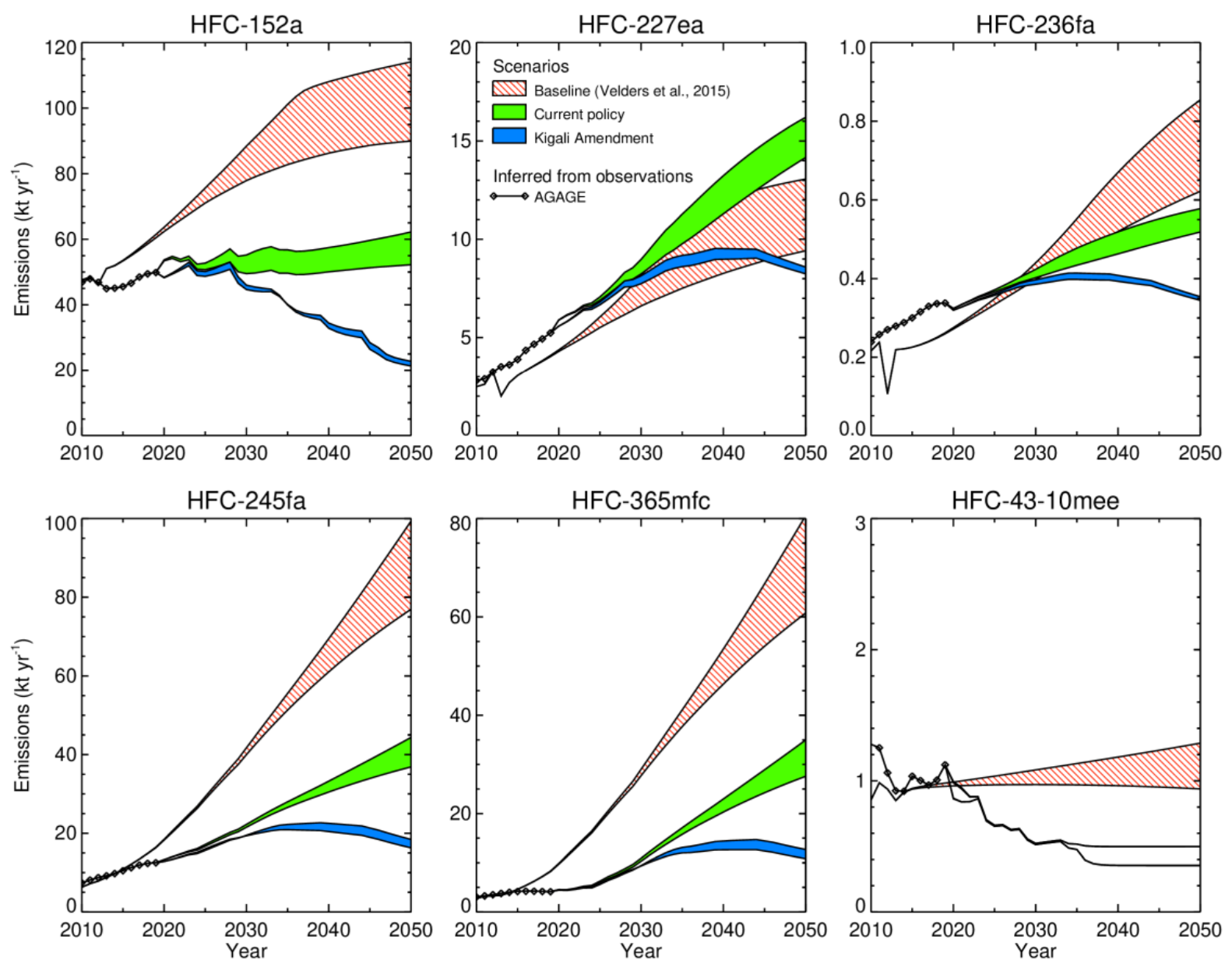

Figure S3: Global total emissions $\left(\mathrm{kt} \mathrm{yr}^{-1}\right.$ ) of HFC-152a, HFC-227ea, HFC-236fa, HFC245fa, HFC-365mfc, and HFC-43-10mee from the 2015 baseline scenario, the "current policy" scenario, and a scenario that follows the phasedown schedules of the 2016 Kigali Amendment (based on the "current policy" scenario). The bands represent the upper and lower ranges of these scenarios. Also shown the emissions inferred from observed mixing ratios from the AGAGE network 